\title{
, \\ High-Performance InGaAs HEMTs on Si Substrates for RF Applications
}

\author{
Bo Wang ${ }^{1,2}\left(\right.$, , Yanfu Wang ${ }^{2}$, Ruize Feng ${ }^{2}$, Haomiao Wei ${ }^{2}$, Shurui Cao ${ }^{2}$, Tong Liu ${ }^{2}$, Xiaoyu Liu ${ }^{2}$, Haiou Li ${ }^{1, *}$, \\ Peng Ding ${ }^{2, *}$ and Zhi Jin ${ }^{2, *}$ \\ 1 Guangxi Key Laboratory of Precision Navigation Technology and Application, \\ Guilin University of Electronic Technology, Guilin 541004, China; wangbo@ime.ac.cn \\ 2 High-Frequency High-Voltage Device and Integrated Circuits Center, Institute of Microelectronics, \\ Chinese Academy of Sciences, Beijing 100029, China; wangyanfu18@mails.ucas.ac.cn (Y.W.); \\ fengruize@ime.ac.cn (R.F.); 202011022902@std.uestc.edu.cn (H.W.); caoshurui@ime.ac.cn (S.C.); \\ liutong@ime.ac.cn (T.L.); liuxiaoyu@ime.ac.cn (X.L.) \\ * Correspondence: lihaiou@guet.edu.cn (H.L.); dingpeng@ime.ac.cn (P.D.); jinzhi@ime.ac.cn (Z.J.)
}

Citation: Wang, B.; Wang, Y.; Feng, R.; Wei, H.; Cao, S.; Liu, T.; Liu, X.; Li, H.; Ding, P.; Jin, Z. High-Performance InGaAs HEMTs on Si Substrates for RF Applications. Electronics 2022, 11, 259. https://doi.org/10.3390/ electronics11020259

Received: 12 December 2021

Accepted: 12 January 2022

Published: 14 January 2022

Publisher's Note: MDPI stays neutral with regard to jurisdictional claims in published maps and institutional affiliations.

Copyright: (C) 2022 by the authors. Licensee MDPI, Basel, Switzerland. This article is an open access article distributed under the terms and conditions of the Creative Commons Attribution (CC BY) license (https:// creativecommons.org/licenses/by/ $4.0 /)$.

\begin{abstract}
In this paper, we have fabricated InGaAs high-electron-mobility transistors (HEMTs) on Si substrates. The InAlAs/InGaAs heterostructures were initially grown on InP substrates by molecular beam epitaxy (MBE), and the adhesive wafer bonding technique was employed to bond the InP substrates to Si substrates, thereby forming high-quality InGaAs channel on Si. The $120 \mathrm{~nm}$ gate length device shows a maximum drain current $\left(\mathrm{I}_{D, \max }\right)$ of $569 \mathrm{~mA} / \mathrm{mm}$, and the maximum extrinsic transconductance $\left(\mathrm{g}_{\operatorname{m}, \max }\right)$ of $1112 \mathrm{mS} / \mathrm{mm}$. The current gain cutoff frequency $\left(\mathrm{f}_{T}\right)$ is as high as $273 \mathrm{GHz}$ and the maximum oscillation frequency $\left(\mathfrak{f}_{M A X}\right)$ reaches $290 \mathrm{GHz}$. To the best of our knowledge, the $g_{m, \max }$ and the $\mathrm{f}_{T}$ of our device are the highest ever reported in InGaAs channel HEMTs on Si substrates at given gate length above $100 \mathrm{~nm}$.
\end{abstract}

Keywords: InGaAs HEMTs; Si substrates; wafer bonding; maximum extrinsic transconductance $\left(\mathrm{g}_{m, \max }\right)$; current gain cutoff frequency $\left(\mathrm{f}_{T}\right)$

\section{Introduction}

The advancement of Si CMOS technology has brought revolutionary changes to microelectronics. Although Si has proven to be very suitable for digital processing and logic applications, it is not omnipotent. Limited by the inherent physical characteristics of the material, $\mathrm{Si}$ is inferior to some other materials such as III-V compound semiconductors in high-frequency applications.

InGaAs displays outstanding carrier transport properties including high electron effective mobility and high sheet carrier density, compared with Si-based materials. InGaAs channel high-electron-mobility transistors (HEMTs) have been used in millimeter-wave and even terahertz monolithic integrated circuits [1-4]. They play key roles in radio-astronomy and deep-space communication. InGaAs channel HEMTs are typically manufactured on either InP or GaAs substrates in commercial production. However, ideally InGaAs channel HEMTs should be integrated on Si substrates to utilize the infrastructure and technology established by Si CMOS to improve monolithic integration and reduce costs. There have been many attempts to integrate the InGaAs channel material on Si substrates. X. Zhou et al. [5] used MOCVD heteroepitaxy technology to grow InGaAs channel material on Si substrate, but required buffer layer thickness greater than $2 \mu \mathrm{m}$ to reduce dislocation density, which was difficult to be compatible with Si CMOS process. N. Waldron et al. [6] developed the aspect-ratio-trapping technique for heterogeneous integration, but the consistency and defects of the materials are difficult to manage. Recently, wafer bonding technology has been widely used to realize the integration of InGaAs channel material on Si substrates [7-10]. Compared with the aforementioned technology, wafer bonding 
can more easily form a high-quality InGaAs channel layer. Heterogeneous integration of InGaAs channel logic transistors on Si substrates has been reported in many published literature [11-14]. However, InGaAs channel RF devices on Si substrates have received little attention.

In this letter, we have developed InGaAs HEMTs on Si substrates for RF applications. The transfer of III-V heterostructures from InP substrates to Si substrates was realized through adhesive wafer bonding technology. Moreover, DC and RF characteristics of the fabricated $120 \mathrm{~nm}$ gate length HEMTs were reported. The fabricated HEMTs show high maximum extrinsic transconductance $\left(\mathrm{g}_{m, \text { max }}\right)$ and current gain cutoff frequency $\left(\mathrm{f}_{T}\right)$ attributable to a $70 \%$ indium content in the channel and a dielectric-assisted T-gate process that strictly suppresses series resistance.

\section{Experiment}

InGaAs HEMTs structures layers on Si substrates were manufactured using adhesive wafer bonding technique, as illustrated in Figure 1. The inverted HEMTs structures were grown using molecular beam epitaxy (MBE) on Semi-Insulting (SI) InP substrates with a $5 \mathrm{~nm}$ InP buffer layer and etching stopper layers (composed of $100 \mathrm{~nm} \mathrm{In}{ }_{0.53} \mathrm{Ga}_{0.47} \mathrm{As}$ and $10 \mathrm{~nm} \mathrm{InP}$ ) between active layers and SI InP substrates. From the InP substrates side to the top, the inverted HEMT structures composed of a $40 \mathrm{~nm}$ Si-doped composite InGaAs cap layer, a $4 \mathrm{~nm}$ InP etching stopper layer, an $8 \mathrm{~nm} \mathrm{In}_{0.53} \mathrm{Al}_{0.47}$ As Schottky barrier layer, Si delta doping layer with $5 \times 10^{12} \mathrm{~cm}^{2}$ doping concentration, a $3 \mathrm{~nm} \operatorname{In}_{0.52} \mathrm{Al}_{0.48} \mathrm{As}$ spacer layer, a $10 \mathrm{~nm} \mathrm{In} \operatorname{~}_{0.7} \mathrm{Ga}_{0.3} \mathrm{As}$ channel layer, and a $200 \mathrm{~nm} \operatorname{In}_{0.52} \mathrm{Al}_{0.48}$ As buffer. To prevent interface degradation, a $30 \mathrm{~nm} \mathrm{SiO}_{2}$ film was deposited by using plasma-enhanced chemical vapor deposition (PECVD). After cleaning, both the InP substrate and Si substrate were coated with an adhesion promoter layer (AP 3000, Dow Chemical) and a benzocyclobutene (BCB) layer (3022-46, Dow Chemical (Midland, MI, USA)). After 15 min of pre-curing, the formal wafer bonding was performed in a nitrogen environment. Finally, the InP substrate and the etching stopper layers were etched with hydrochloric acid and phosphorus acid/hydrogen peroxide mixed solution, and the InGaAs HEMTs structures layers were completed on the Si substrate. Figure 2 shows a $10 \mu \mathrm{m} \times 10 \mu \mathrm{m}$ atomic force microscopy (AFM) scan of the $\mathrm{n}$-InGaAs cap layer after back etching. The root mean square (RMS) roughness of the cap layer is $0.236 \mathrm{~nm}$, which is much lower than that grown by MOCVD $[15,16]$.

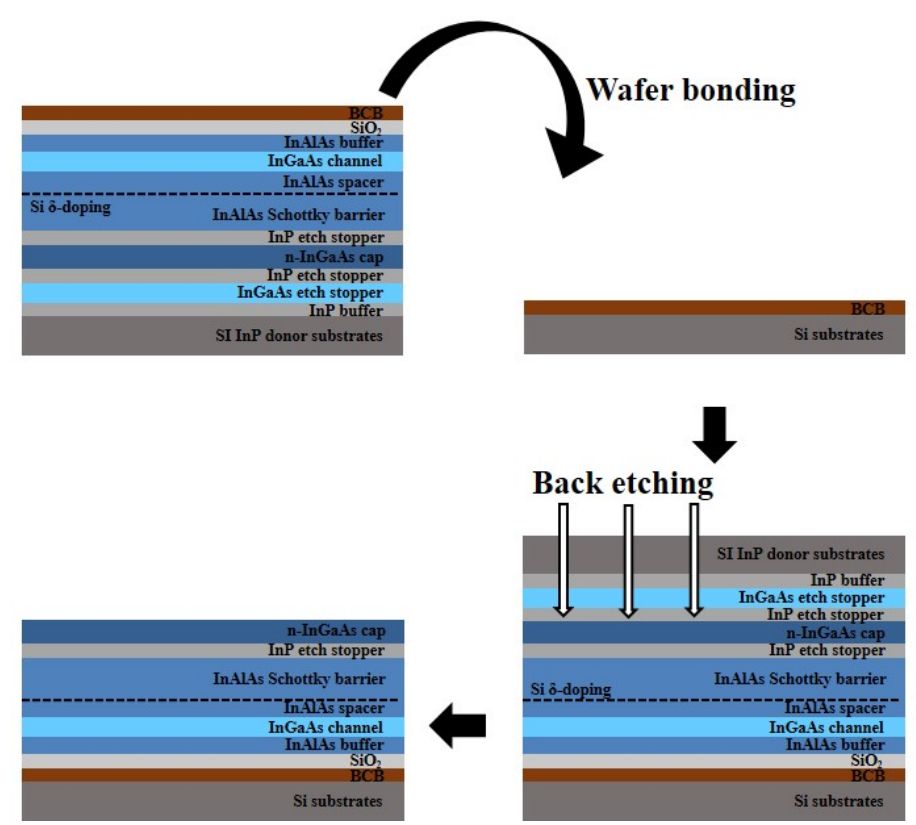

Figure 1. Process flow for the InGaAs HEMTs structures layers on Si substrates fabrication by using adhesive wafer bonding technique. 


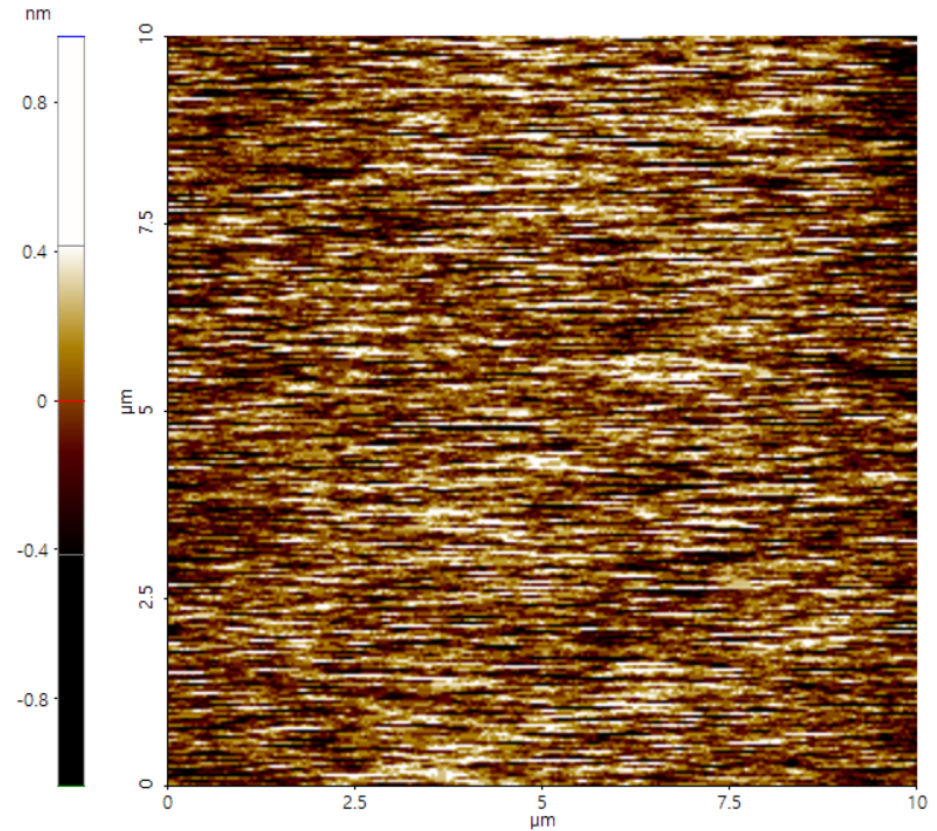

Figure 2. AFM images of the n-InGaAs cap layer for the scan area of $10 \mu \mathrm{m} \times 10 \mu \mathrm{m}$.

The device structure of InGaAs HEMTs on Si substrates and the band diagram of the heterojunction are shown in Figure 3. In the device fabrication, mesa isolation was achieved using phosphorus acid/hydrogen peroxide mixed solution and hydrochloric acid/phosphorus acid mixed solution by wet chemical etching. Optical lithography was used to define S/D ohmic contacts, which were made of $\mathrm{Ti} / \mathrm{Pt} / \mathrm{Au}$ metal. Afterward, as a hard mask for gate recess, around $5 \mathrm{~nm} \mathrm{SiO}_{2}$ was formed on the surface using PECVD. The T-shaped gating process consisted of gate e-beam lithography, $\mathrm{SiO}_{2}$ etching, recess, and metallization. E-beam lithography was used to define the gate pattern, which was then transferred to the $\mathrm{SiO}_{2}$ layer via reactive ion etching (RIE). The gate recess was formed by wet chemical etching with a mixture of phosphoric acid/hydrogen peroxide solution. By strictly controlling the width of the gate recess to achieve the lowest possible series resistance.The $\mathrm{Ti} / \mathrm{Pt} / \mathrm{Au} \mathrm{T}$-shaped gate metal was e-beam evaporated and lifted off, with the gate area defined as $2 \times(0.12 \times 50) \mu \mathrm{m}^{2}$. Finally, as surface passivation in the active region, a $20 \mathrm{~nm} \mathrm{Si}_{3} \mathrm{~N}_{4}$ layer was formed through PECVD. The cross-sectional focused ion beam (FIB) image of the T-gate region of the fabricated HEMTs on Si substrates is shown in Figure 4 . The gate length can be determined as $120 \mathrm{~nm}$.

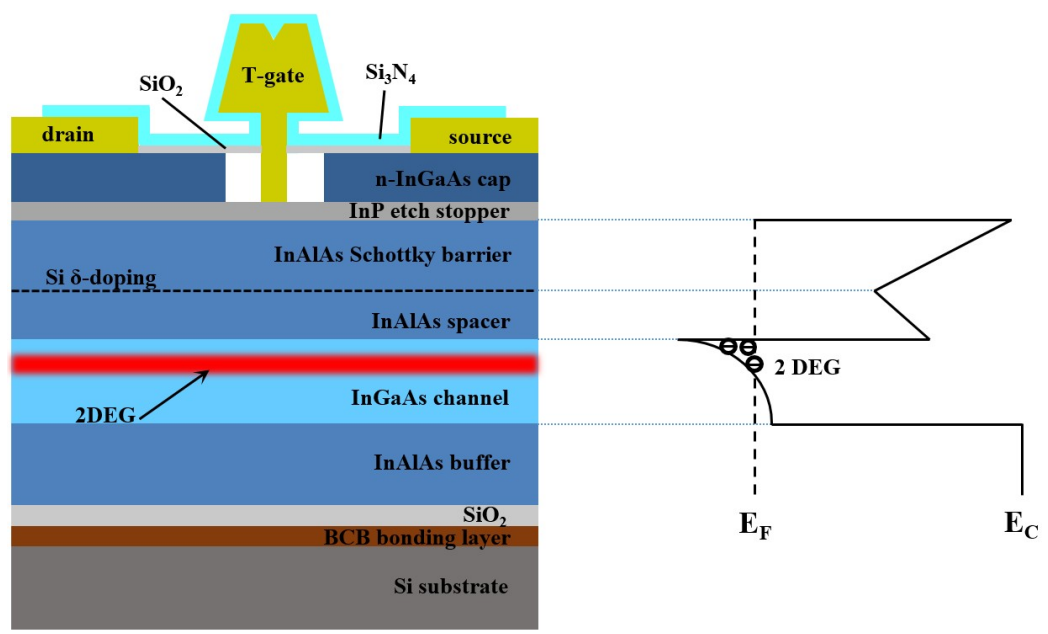

Figure 3. The schematic cross section of the passivated InGaAs HEMTs on Si substrates and the band diagram of the heterojunction. 


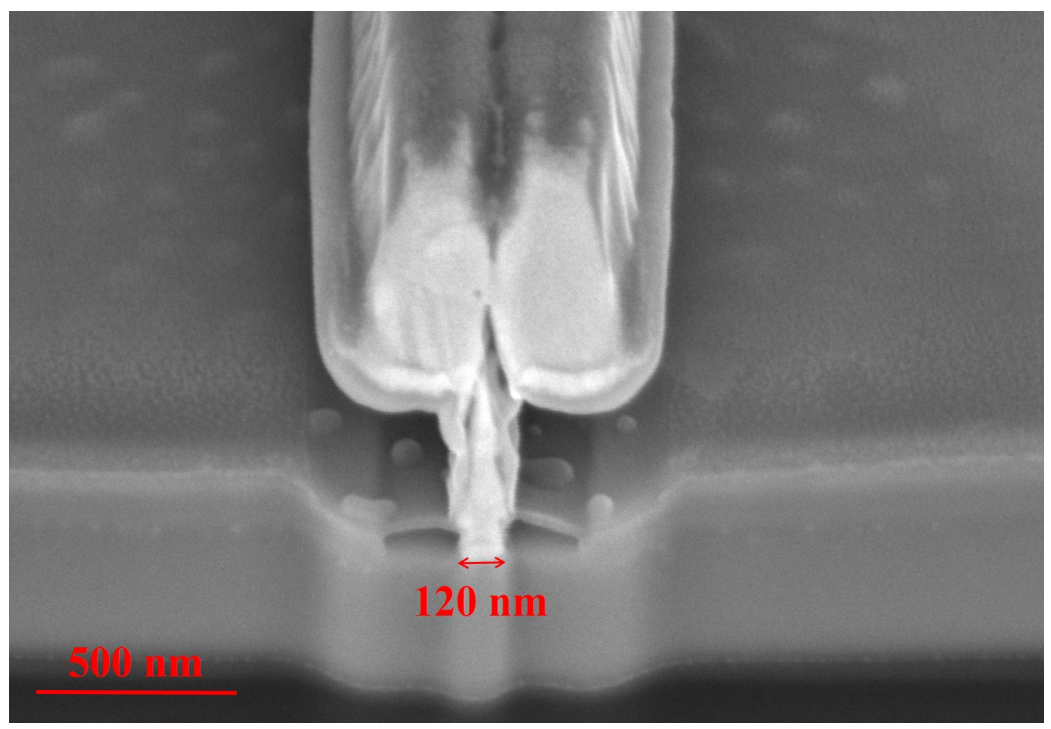

Figure 4. Cross-sectional FIB image of $120 \mathrm{~nm}$ T-gate.

\section{Result and Discussion}

The DC performance of devices is carried out at room temperature through the HP4142 semiconductor parameter analyzer. Figure 5 shows the $\mathrm{I}_{D}-\mathrm{V}_{D}$ output characteristics for a $120 \mathrm{~nm}$ gate length InGaAs HEMTs on Si substrates at room temperature with a gate bias from $-1 \mathrm{~V}$ to $0 \mathrm{~V}$ in the step of $0.1 \mathrm{~V}$. The device demonstrates superior pinch-off characteristics. The maximum drain current $\left(\mathrm{I}_{D, \text { max }}\right)$ is $569 \mathrm{~mA} / \mathrm{mm}$ at $\mathrm{V}_{G}=0 \mathrm{~V}$ and $\mathrm{V}_{D}=0.8 \mathrm{~V}$.

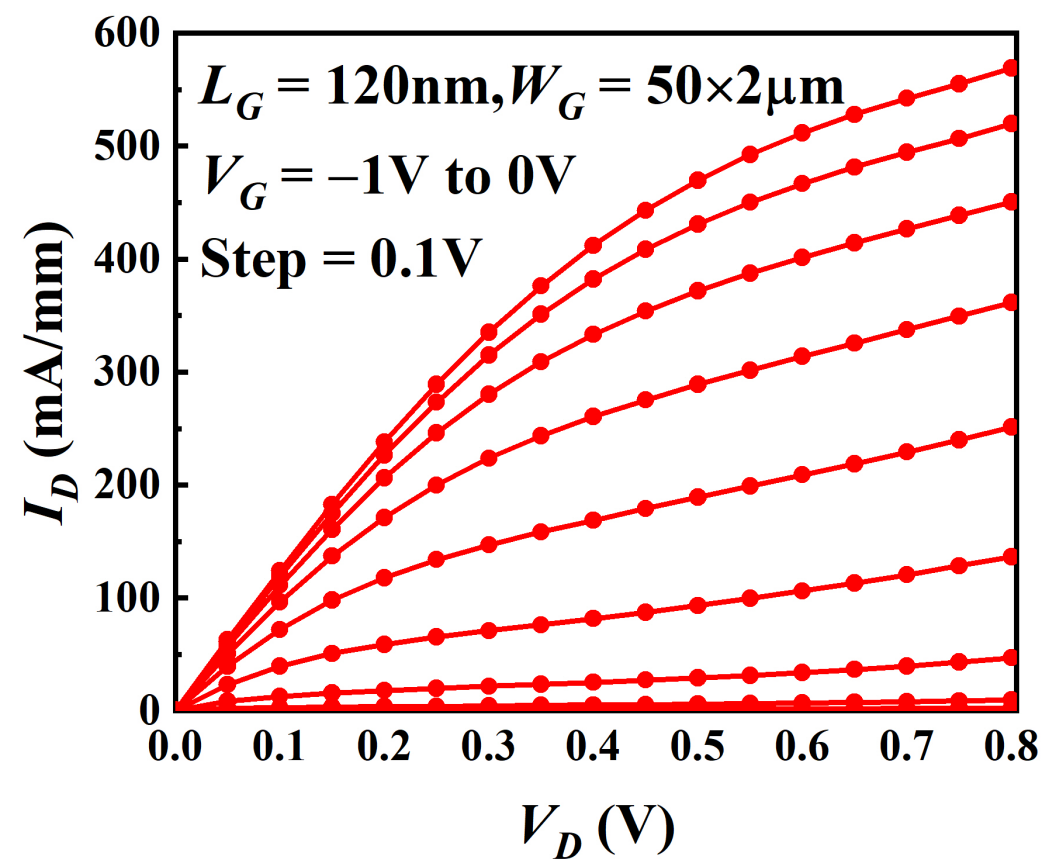

Figure 5. Output characteristics of the InGaAs HEMTs on Si substrates.

Figure 6 shows the transfer characteristic of InGaAs HEMTs on Si substrates. Benefit from an indium content of $70 \%$ in the channel, the maximum extrinsic transconductance of $1112 \mathrm{mS} / \mathrm{mm}$ was achieved at $\mathrm{V}_{G}=-0.4 \mathrm{~V}$ and $\mathrm{V}_{D}=0.8 \mathrm{~V}$. The threshold voltage of InGaAs HEMTs is about $-0.63 \mathrm{~V}$. The subthreshold-swing $(S)$ and drain induced barrier lowering (DIBL) were $150 \mathrm{mV} / \mathrm{dec}$ and $100 \mathrm{mV} / \mathrm{V}$, respectively. 


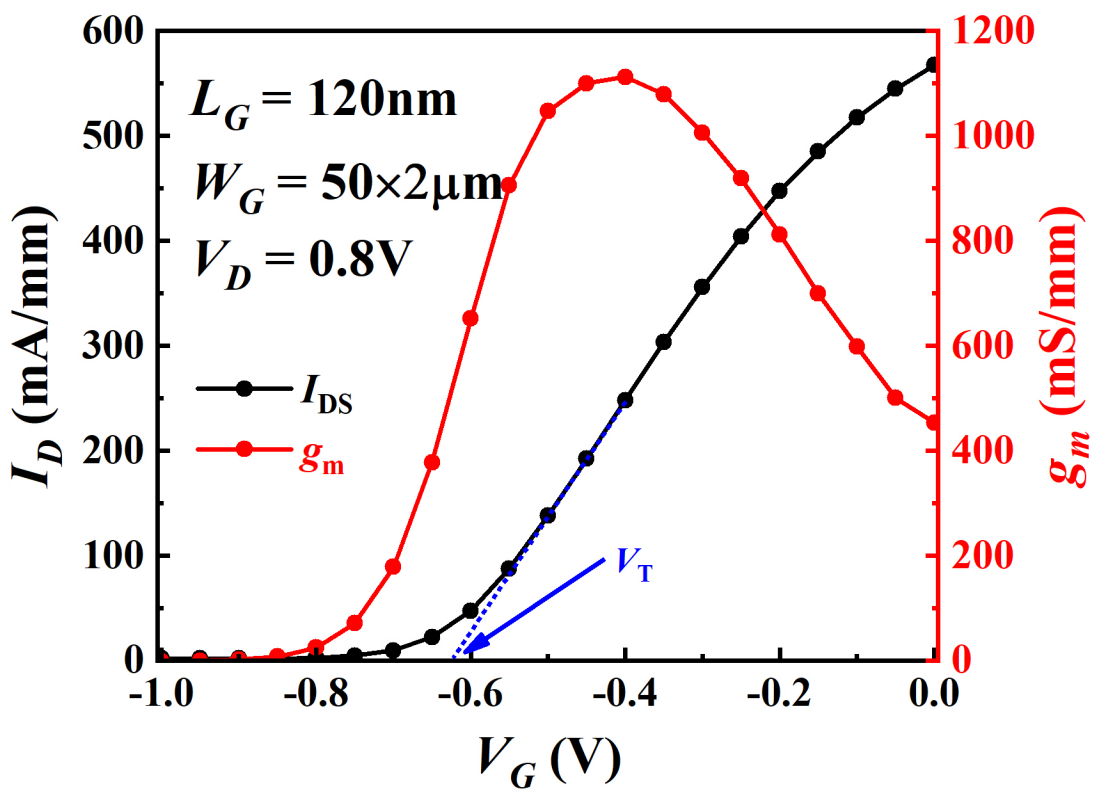

Figure 6. Transfer characteristics of the InGaAs HEMTs on Si substrates.

Figure 7 shows the gate current leakage characteristic of the HEMTs. Although the manufactured devices exhibit sufficiently small gate leakage currents, impact ionzation cannot be ignored at high $\mathrm{V}_{D}$. Impact ionization has been shown to have a negative impact on the RF and noise characteristics of HEMTs [17]. Future experiments can suppress impact ionzation by using compound channels [18].

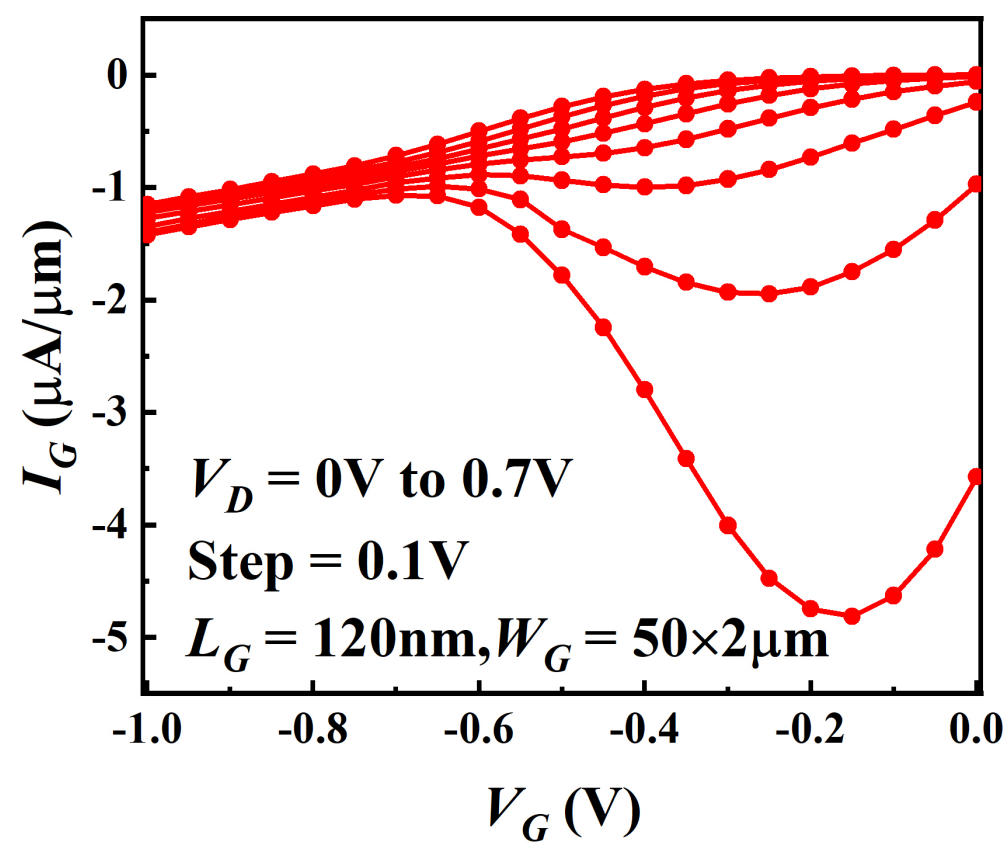

Figure 7. Gate current leakage characteristic of the InGaAs HEMTs on Si substrates.

The RF performance of devices is carried out at room temperature through the Agilent E8363B PNA vector network analyzer from $0.1 \mathrm{GHz}$ to $40 \mathrm{GHz}$. On-wafer S-parameters of the InGaAs HEMTs on Si substrates were measured and extracted. Before measurement, the devices were de-embedded by using on-wafer open and short pad structures to exclude the parasitic effect. The values of current gain $\left(\mathrm{H}_{21}\right)$, maximum available gain and maxi- 
mum stable gain (MAG/MSG), Mason's unilateral gain (U), and stability factor (k) were calculated using the following Equations (1)-(6), and were plotted in Figure 8.

$$
\begin{gathered}
\mathrm{H}_{21}=\frac{-2 S_{21}}{\left(1-S_{11}\right)\left(1+S_{22}\right)+S_{12} S_{21}}, \\
\mathrm{MAG}=\frac{\left|S_{21}\right|}{\left|S_{12}\right|}\left(k-\sqrt{k^{2}-1}\right) \quad k>1,|\Delta|<1 \\
\mathrm{MSG}=\frac{\left|S_{21}\right|}{\left|S_{12}\right|} \quad k<1,|\Delta|<1, \\
\mathrm{U}=\frac{\left|\left(S_{21} / S_{12}\right)-1\right|^{2}}{2 k\left|S_{21} / S_{12}\right|-2 \operatorname{Re}\left[S_{21} / S_{12}\right]} \\
k=\frac{1-\left|S_{11}\right|^{2}-\left|S_{22}\right|^{2}+|\Delta|^{2}}{2 \cdot\left|S_{12} S_{21}\right|}, \\
\Delta=S_{11} S_{22}-S_{12} S_{21},
\end{gathered}
$$

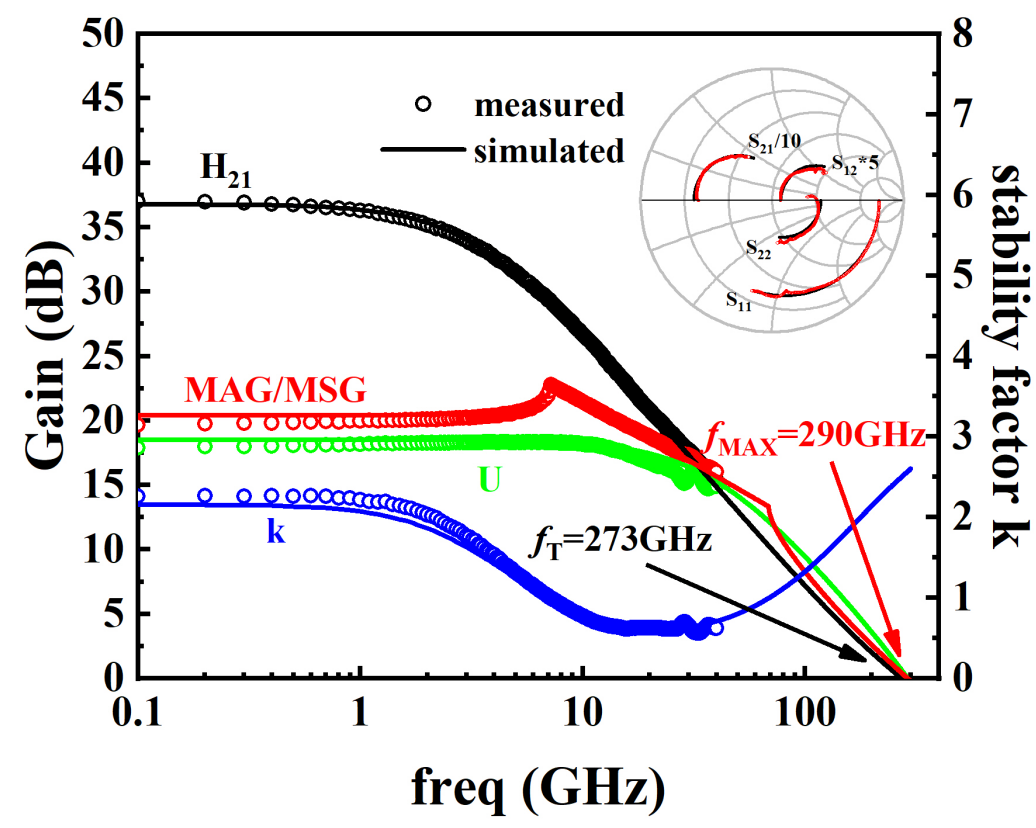

Figure 8. RF characteristics of the HEMTs at $\mathrm{V}_{G}=-0.4 \mathrm{~V}$ and $\mathrm{V}_{D}=0.8 \mathrm{~V}$.

In addition, the small-signal model of HEMTs fabricated on Si substrates was made at the $\mathrm{g}_{m, \max }$ point of $\mathrm{V}_{\mathrm{G}}=-0.4 \mathrm{~V}$ and $\mathrm{V}_{D}=0.8 \mathrm{~V}$. The device modeling parameters are tweaked until the S-parameters matche closely with the measured parameters, as shown in Figure 8. Since the limitation of test frequency, $\mathrm{f}_{T}$ and maximum oscillation frequency $\left(\mathrm{f}_{M A X}\right)$, were obtained by extrapolating the simulated curve of $\mathrm{H}_{21}$ and MAG/MSG. The extrapolated $\mathrm{f}_{T}$ and $\mathrm{f}_{M A X}$ were 273 and $290 \mathrm{GHz}$, respectively. The $\mathrm{f}_{T}$ and $\mathrm{f}_{M A X}$ are expressed by Equations (7) and (8).

$$
\begin{aligned}
& \mathrm{f}_{T}=\frac{\mathrm{g}_{m i}}{2 \pi\left(C_{g s}+C_{g d}\right)\left[1+\mathrm{g}_{d s}\left(R_{s}+R_{d}\right)\right]+C_{g d} \cdot \mathrm{g}_{m i}\left(R_{s}+R_{d}\right)}, \\
& \mathrm{f}_{M A X}=\frac{f_{T, i n t}}{\sqrt{4 g_{d s}\left(R_{g}+R_{i}+R_{s}\right)+\frac{2 C_{g d}}{C_{g s}}\left(\frac{C_{g d}}{C_{g s}}+\mathrm{g}_{m i}\left(R_{i}+R_{s}\right)\right.}},
\end{aligned}
$$

where $g_{m i}$ is the intrinsic transconductance, $C_{g s}$ and $C_{g d}$ are the parasitic capacitances from gate to source and gate to drain, respectively; $g_{d s}$ is conductance between drain and source; 
$R_{s}, R_{d}$ and $R_{g}$ are the parasitic resistances of source, drain and gate, respectively. $R_{i}$ is the intrinsic resistance in the channel region. $\mathrm{f}_{T, \text { int }}$ represents the cut-off frequency of the intrinsic part of HEMTs without parasitic resistance and capacitance. From Equations (7) and (8) we can know that $C_{g s}, C_{g d}, R_{s}$ and $R_{d}$ are the key parasitic parameters that affect $\mathrm{f}_{T}$ and $\mathrm{f}_{M A X}$ [19]. Especially, $R_{s}$ and $R_{d}$ have a great impact on $\mathrm{f}_{T}$. In our device manufacturing process, $R_{S}$ and $R_{d}$ were effectively restricted by controlling the etching of the gate recesses, thus improving $\mathrm{f}_{T}$. The extraction of parameters through the small-signal model further confirms our viewpoint. Table 1 summarizes the small-signal modeling parameters of InGaAs HEMTs on Si substrates at the $\mathrm{g}_{m, \max }$ point of $\mathrm{V}_{G}=-0.4 \mathrm{~V}$ and $\mathrm{V}_{D}=0.8 \mathrm{~V}$.

Table 1. The parameters of the small-signal equivalent circuit of devices.

\begin{tabular}{cccccccccc}
\hline$C_{g s}(\mathrm{fF})$ & $C_{g d}(\mathrm{fF})$ & $C_{d s}(\mathrm{fF})$ & $\mathrm{g}_{d s}(\mathrm{mS})$ & $R_{s}(\Omega)$ & $R_{d}(\Omega)$ & $R_{g}(\Omega)$ & $R_{i}(\Omega)$ & $g_{m i}(\mathrm{mS})$ & $T a u(\mathrm{fs})$ \\
\hline 62.1 & 9.5 & 11.5 & 10 & 1.6 & 4.5 & 3 & 7.5 & 116 & 400 \\
\hline
\end{tabular}

The performance of our fabricated device and other reported InGaAs channel transistors on Si substrates are summarized in Table 2. Our $120 \mathrm{~nm}$ gate length device exhibits $\mathrm{g}_{m, \max }=1112 \mathrm{mS} / \mathrm{mm}$ and $\mathrm{f}_{T}=273 \mathrm{GHz}$, which are the highest values reported in the InGaAs channel transistors on $\mathrm{Si}$ substrates at given $\mathrm{L}_{G}$ above $100 \mathrm{~nm}$ as far as we know.

Table 2. Comparison with published InGaAs channel transistors on Si substrates.

\begin{tabular}{ccccccc}
\hline Reference & $\begin{array}{c}\mathrm{L}_{G} \\
(\mathbf{n m})\end{array}$ & Channel & $\begin{array}{c}\mathbf{I}_{\boldsymbol{D}, \max } \\
(\mathbf{m A} / \mathbf{m m})\end{array}$ & $\begin{array}{c}\mathrm{g}_{\text {m,max }} \\
\mathbf{( m S / m m})\end{array}$ & $\begin{array}{c}\mathrm{f}_{\boldsymbol{T}} \\
(\mathbf{G H z})\end{array}$ & $\begin{array}{c}\mathrm{f}_{M A X} \\
(\mathbf{G H z})\end{array}$ \\
\hline$[7]$ & 125 & $\mathrm{In}_{0.53} \mathrm{Ga}_{0.47} \mathrm{As} / \mathrm{InAs} / \mathrm{In}_{0.53} \mathrm{Ga}_{0.47} \mathrm{As}$ & 650 & 500 & 227 & 187 \\
{$[15]$} & 150 & $\mathrm{In}_{0.30} \mathrm{Ga}_{0.70} \mathrm{As}$ & 160 & - & 60 & - \\
{$[20]$} & 400 & $\mathrm{In}_{0.18} \mathrm{Ga}_{0.82} \mathrm{As}$ & 150 & 155 & 5.5 & 13 \\
{$[21]$} & 120 & $\mathrm{In}_{0.53} \mathrm{Ga}_{0.47} \mathrm{As}$ & 450 & 770 & 185 & 290 \\
This work & 120 & $\mathrm{In}_{0.7} \mathrm{Ga}_{0.3} \mathrm{As}$ & 569 & 1112 & 273 \\
\hline
\end{tabular}

\section{Conclusions}

We have demonstrated InGaAs HEMTs on Si substrates for RF applications. The $120 \mathrm{~nm}$ gate length device exhibits good DC and RF performances featuring $\mathrm{g}_{\operatorname{m}, \max }=1112 \mathrm{mS} / \mathrm{mm}$ and $f_{T}=273 \mathrm{GHz}$, which are the highest values reported in InGaAs channel transistors on Si substrates above $L_{G}=100 \mathrm{~nm}$. These results show the potential for InGaAs HEMTs in future high-frequency applications on Si substrates.

Author Contributions: Conceptualization, P.D.; methodology, B.W., P.D. and Y.W.; validation, S.C. and H.W.; formal analysis, B.W. and P.D.; investigation, X.L. and T.L.; data curation, B.W., R.F. and Y.W.; writing - original draft preparation, B.W.; writing-review and editing, B.W. and P.D.; visualization, B.W.; supervision, H.L. and Z.J.; project administration, P.D.; funding acquisition, H.L. and Z.J. All authors have read and agreed to the published version of the manuscript.

Funding: This work is supported by the National Natural Science Foundation of China (No. 61874036, No. 62174041, No. 61434006), the Open Project of State Key Laboratory of ASIC and System (No. KVH1233021), the Guangxi Innovation Research Team Project (No. 2018GXNSFGA281004, No. 2018GXNSFBA281152), the Guangxi Innovation-Driven Development Special Fund Project (No. AA19254015), the Opening Foundation of the State Key Laboratory of Advanced Materials and Electronic Components (No. FHR-JS-201909007), and the Guangxi Key Laboratory of Precision Navigation Technology and Application Project (No. DH202020, No. DH202001, No. DH201906).

Data Availability Statement: The data presented in this study are available on request from the corresponding author.

Conflicts of Interest: The authors declare no conflict of interest. 


\section{References}

1. Liu, Y.; Zhang, B.; Feng, Y.; Zhao, X.; Wang, J.; Ji, D.; Yang, Y.; Fan, Y. A G-band Balanced Power Amplifier based on InP HEMT Technology. In Proceedings of the 2020 IEEE MTT-S International Wireless Symposium (IWS), Shanghai, China, 20-23 September 2020; pp. 1-3. [CrossRef]

2. Hamada, H.; Tsutsumi, T.; Matsuzaki, H.; Sugiyama, H.; Nosaka, H. 475-GHz 20-dB-Gain InP-HEMT Power Amplifier Using Neutralized Common-Source Architecture. In Proceedings of the 2020 IEEE/MTT-S International Microwave Symposium (IMS), Los Angeles, CA, USA, 4-6 August 2020; pp. 1121-1124. [CrossRef]

3. Hamada, H.; Tsutsumi, T.; Itami, G.; Sugiyama, H.; Matsuzaki, H.; Okada, K.; Nosaka, H. 300-GHz 120-Gb/s Wireless Transceiver with High-Output-Power and High-Gain Power Amplifier Based on 80-nm InP-HEMT Technology. In Proceedings of the 2019 IEEE BiCMOS and Compound semiconductor Integrated Circuits and Technology Symposium (BCICTS), Nashville, TN, USA, 3-6 November 2019; pp. 1-4. [CrossRef]

4. Mei, X.; Yoshida, W.; Lange, M.; Lee, J.; Zhou, J.; Liu, P.H.; Leong, K.; Zamora, A.; Padilla, J.; Sarkozy, S.; Lai, R.; Deal, W.R. First Demonstration of Amplification at $1 \mathrm{THz}$ Using 25-nm InP High Electron Mobility Transistor Process. IEEE Electron. Device Lett. 2015, 36, 327-329. [CrossRef]

5. Zhou, X.; Li, Q.; Tang, C.W.; Lau, K.M. 30nm enhancement-mode In0.53Ga0.47As MOSFETs on Si substrates grown by MOCVD exhibiting high transconductance and low on-resistance. In Proceedings of the 2012 International Electron Devices Meeting, San Francisco, CA, USA, 10-13 December 2012; pp. 32.5.1-32.5.4. [CrossRef]

6. Waldron, N.; Wang, G.; Nguyen, N.D.; Orzali, T.; Merckling, C.; Brammertz, G.; Ong, P.; Winderickx, G.; Hellings, G.; Eneman, G.; et al. Integration of InGaAs Channel n-MOS Devices on 200mm Si Wafers Using the Aspect-Ratio-Trapping Technique. ECS Trans. 2012, 45, 115-128. [CrossRef]

7. Jeong, J.; Kim, S.K.; Kim, J.; Geum, D.M.; Park, J.; Jang, J.H.; Kim, S. Stackable InGaAs-on-Insulator HEMTs for Monolithic 3-D Integration. IEEE Trans. Electron Devices 2021, 68, 2205-2211. [CrossRef]

8. Tessmann, A.; Leuther, A.; Heinz, F.; Bernhardt, F.; John, L.; Massler, H.; Czornomaz, L.; Merkle, T. 20-nm In0.8Ga0.2As MOSHEMT MMIC Technology on Silicon. IEEE J. Solid-State Circuits 2019, 54, 2411-2418. [CrossRef]

9. Zota, C.B.; Convertino, C.; Baumgartner, Y.; Sousa, M.; Caimi, D.; Czornomaz, L. High Performance Quantum Well InGaAs-On-Si MOSFETs With sub-20 nm Gate Length For RF Applications. In Proceedings of the 2018 IEEE International Electron Devices Meeting (IEDM), San Francisco, CA, USA, 1-5 December 2018; pp. 39.4.1-39.4.4. [CrossRef]

10. Vandooren, A.; Franco, J.; Parvais, B.; Wu, Z.; Witters, L.; Walke, A.; Li, W.; Peng, L.; Desphande, V.; Bufler, F.M.; et al. 3D sequential stacked planar devices on $300 \mathrm{~mm}$ wafers featuring replacement metal gate junction-less top devices processed at $525^{\circ} \mathrm{C}$ with improved reliability. In Proceedings of the 2018 IEEE Symposium on VLSI Technology, Honolulu, HI, USA, 18-22 June 2018; pp. 69-70. [CrossRef]

11. Lee, S.; Kim, S.K.; Han, J.; Song, J.D.; Jun, D.; Kim, S. Epitaxial Lift-Off Technology for Large Size III-V-on-Insulator Substrate. IEEE Electron. Device Lett. 2019, 40, 1732-1735. [CrossRef]

12. Kim, S.K.; Shim, J.; Geum, D.; Kim, J.; Kim, C.Z.; Kim, H.; Song, J.D.; Choi, S.; Kim, D.H.; Choi, W.J.; et al. Impact of Ground Plane Doping and Bottom-Gate Biasing on Electrical Properties in In0.53Ga0.47As-OI MOSFETs and Donor Wafer Reusability Toward Monolithic 3-D Integration With In0.53Ga0.47As Channel. IEEE Trans. Electron Devices 2018, 65, 1862-1868. [CrossRef]

13. Convertino, C.; Zota, C.; Sant, S.; Eltes, F.; Sousa, M.; Caimi, D.; Schenk, A.; Czornomaz, L. InGaAs-on-Insulator FinFETs with Reduced Off-Current and Record Performance. In Proceedings of the 2018 IEEE International Electron Devices Meeting (IEDM), San Francisco, CA, USA, 1-5 December 2018; pp. 39.2.1-39.2.4. [CrossRef]

14. Takagi, S.; Ahn, D.H.; Gotow, T.; Noguchi, M.; Nishi, K.; Kim, S.; Yokoyama, M.; Chang, C.; Yoon, S.; Yokoyama, C.; et al. III-V-based low power CMOS devices on Si platform. In Proceedings of the 2017 IEEE International Conference on IC Design and Technology (ICICDT), Austin, TX, USA, 23-25 May 2017; pp. 1-4. [CrossRef]

15. Yadav, S.; Kumar, A.; Nguyen, X.S.; Lee, K.H.; Liu, Z.; Xing, W.; Masudy-Panah, S.; Lee, K.; Tan, C.S.; Fitzgerald, E.A.; et al. High mobility In0.30Ga0.70As MOSHEMTs on low threading dislocation density $200 \mathrm{~mm}$ Si substrates: A technology enabler towards heterogeneous integration of low noise and medium power amplifiers with Si CMOS. In Proceedings of the 2017 IEEE International Electron Devices Meeting (IEDM), San Francisco, CA, USA, 2-6 December 2017; pp. 17.4.1-17.4.4. [CrossRef]

16. Nguyen, X.S.; Yadav, S.; Lee, K.H.; Kohen, D.; Kumar, A.; Made, R.I.; Lee, K.E.K.; Chua, S.J.; Gong, X.; Fitzgerald, E.A. MOCVD Growth of High Quality InGaAs HEMT Layers on Large Scale Si Wafers for Heterogeneous Integration With Si CMOS. IEEE Trans. Semicond. Manuf. 2017, 30, 456-461. [CrossRef]

17. Reuter, R.; Agethen, M.; Auer, U.; Waasen, S.v.; Peters, D.; Brockerhoff, W.; Tegude, F.J. Investigation and modeling of impact ionization with regard to the RF and noise behavior of HFET. IEEE Trans. Microw. Theory Tech. 1997, 45, 977-983. [CrossRef]

18. Ruiz, D.C.; Saranovac, T.; Han, D.; Ostinelli, O.; Bolognesi, C.R. Impact Ionization Control in 50 nm Low-Noise High-Speed InP HEMTs with InAs Channel Insets. In Proceedings of the 2019 IEEE International Electron Devices Meeting (IEDM), San Francisco, CA, USA, 7-11 December 2019; pp. 9.3.1-9.3.4. [CrossRef]

19. del Alamo, J.A. Nanometre-scale electronics with III-V compound semiconductors. Nature 2011, 479, $317-323$. nature10677. [CrossRef] [PubMed] 
20. Chang, E.Y.; Huang, J.C.; Lin, Y.C.; Hsieh, Y.C.; Chang, C.Y. AlGaAs/InGaAs High Electron Mobility Transistor Grown on Si Substrate with Ge/GexSi1-xMetamorphic Buffer Layers. Jpn. J. Appl. Phys. 2008, 47, 7069-7072. [CrossRef]

21. Bollaert, S.; Wallaert, X.; Lepilliet, S.; Cappy, A.; Jalaguier, E.; Pocas, S.; Aspar, B. $0.12 \mu \mathrm{m}$ transferred-substrate In0.52Al0.48As/In0.53Ga0.47As HEMTs on silicon wafer. IEEE Electron. Device Lett. 2002, 23, 73-75. [CrossRef] 